\title{
Uranyl-chelating peptides to help understanding uranium toxicity at a molecular level
}

\author{
Fanny Laporte, ${ }^{1}$ Matthieu Stark, ${ }^{1}$ Colette Lebrun, ${ }^{1}$ Stéphane Oros, ${ }^{1}$ Nathalie Sisommay, ${ }^{1}$ \\ Vicky Gathu, ${ }^{1}$ Pier Lorenzo Solari, ${ }^{5}$ Gaëlle Creff, ${ }^{3}$ Jérôme Roques, ${ }^{4}$ Christophe Den \\ Auwer, ${ }^{3}$ Claude Vidaud $^{2}$ and Pascale Delangle ${ }^{1, *}$ \\ ${ }^{1}$ INAC-SyMMES, Univ. Grenoble Alpes, CEA, CNRS, 38000 Grenoble, France \\ ${ }^{2}$ BIAM, CEA, CNRS, Aix-Marseille Université, 13108 Saint-Paul-lez-Durance, France \\ ${ }^{3}$ Institut de Chimie de Nice, Université Côte d'Azur, 06108 Nice, France \\ ${ }^{4}$ Institut de Physique Nucléaire d'Orsay, CNRS-IN2P3, Univ. Paris-Sud, Univ. Paris-Saclay, France \\ ${ }^{5}$ Synchrotron SOLEIL, L'orme des Merisiers, Saint-Aubin, 91192 Gif-sur-Yvette, France
}

\section{Context}

Uranium is a natural element widely found in the environment, due to both natural occurrence in mineral ores or in sea water and industrial applications. The production of nuclear energy uses enriched uranium in ${ }^{235} \mathrm{U}$ for nuclear fission. Despite its ubiquitous distribution, uranium has no essential role in living organisms and presents radiological and chemical toxicities. Despite significant recent advances in the field, there is still a serious lack of knowledge about the molecular interactions responsible for uranium toxicity. The underlying mechanisms need to be unravelled to predict the effect of uranium on living organisms and also to help in designing efficient detoxification agents, to be used in case of dirty bombs or accidental release of uranium in the environment.

\section{Design of biomimetic peptides}

At the CIBEST lab, we propose a biomimetic approach to help understanding the interactions of metals with biological molecules, relevant to their regulation and toxicity.[1,2] This strategy was applied for uranium, which most stable form in vivo is the uranyl cation, $\mathrm{UO}_{2}{ }^{2+}$, which prefers four to six oxygen donors in its equatorial plane, perpendicular to O-U-O bonds. Short peptide sequences are used as simple models of metal-binding sites in proteins to get structural and thermodynamic data, which are not accessible directly with large biological molecules. Cyclic constrained peptide scaffolds that orient metal-coordinating groups found in proteins toward the equatorial plane of the uranyl cation revealed to be highly effective uranyl-binding peptides.[3]

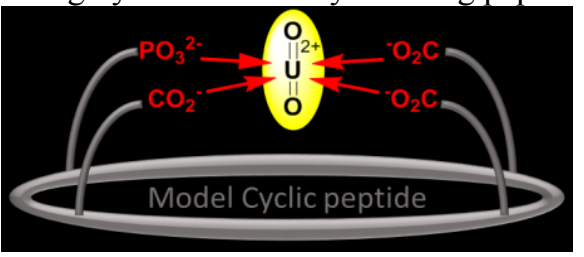

*Corresponding author: pascale.delangle@cea.fr 


\section{Results}

A combination of synthesis, analytical chemistry, X-Absorption Spectroscopy and theoretical calculations allowed us to correlate the amino acid sequence to the stability of the uranyl complexes. Uranium-coordinating amino acids with side-chains containing oxygen donors, such as aspartic acids, glutamic acids and phosphoserines were inserted in the cyclic peptide sequences. The largest uranyl complexes stabilities were obtained when four coordinating amino acids were converging to the uranyl equatorial plane.[3-5]

Importantly, phosphate groups significantly enhance the affinity of the biomimetic peptides for uranyl, which strongly supports the importance of phosphoamino acids in uranyl binding in proteins. Therefore, our biomimetic approach reinforces the relevance of considering phosphoproteins such as osteopontin as potential uranyl targets in vivo.[6-8]

\section{Acknowledgements}

This work was supported by the toxicology and NRBC programs of CEA and the LabEx ARCANE (Grant ANR-11-LABX-0003-01).

\section{References}

1. O. Sénèque, P. Rousselot-Pailley, A.M. Pujol, D. Boturyn, S. Crouzy, O. Proux, A. Manceau, C. Lebrun, P. Delangle, Inorg. Chem., 57, 2705 (2018)

2. A.S. Jullien, C. Gateau, C. Lebrun, P. Delangle, Inorg. Chem., 54, 2339 (2015)

3. C. Lebrun, M. Starck, V. Gathu, Y. Chenavier, P. Delangle, Chem. Eur. J., 20, 16566 (2014)

4. M. Starck, F. A. Laporte, S. Oros, N. Sisommay, V. Gathu, P. L. Solari, G. Creff, J. Roques, C. Den Auwer, C. Lebrun, P. Delangle, Chem. Eur. J., 23, 5288 (2017)

5. M. Starck, N. Sisommay, F. A. Laporte, S. Oros, C. Lebrun, P. Delangle, Inorg. Chem., 24, 11557 (2015)

6. L. Qi, C. Basset, O. Averseng, E. Quemeneur, A. Hagege, C. Vidaud, Metallomics, 6, $166(2014)$

7. T. N. S. Huynh, C. Vidaud, A. Hagege, Metallomics, 8, 1185 (2016).

8. F. Laporte, PhD thesis, Univ. Grenoble Alpes (2017). 